\title{
A randomised controlled trial of cognitive behavioural treatment for obsessive compulsive disorder in children and adolescents
}

Article

Accepted Version

Williams, T. I., Salkovskis, P.M., Forrester, E., Turner, S., White, H. and Allsopp, M. (2010) A randomised controlled trial of cognitive behavioural treatment for obsessive compulsive disorder in children and adolescents. European Child and Adolescent Psychiatry, 19 (5). pp. 449-456. ISSN 1018-8827 doi: https://doi.org/10.1007/s00787-009-0077-9 Available at https://centaur.reading.ac.uk/18188/

It is advisable to refer to the publisher's version if you intend to cite from the work. See Guidance on citing.

To link to this article DOI: http://dx.doi.org/10.1007/s00787-009-0077-9

Publisher: Springer Verlag

All outputs in CentAUR are protected by Intellectual Property Rights law, including copyright law. Copyright and IPR is retained by the creators or other copyright holders. Terms and conditions for use of this material are defined in the End User Agreement. 


\section{www.reading.ac.uk/centaur}

\section{CentAUR}

Central Archive at the University of Reading

Reading's research outputs online 


\section{Editorial Manager(tm) for European Child \& Adolescent Psychiatry Manuscript Draft}

Manuscript Number: ECAP-D-08-00177R1

Title: A randomised controlled trial of cognitive behavioural treatment for obsessive compulsive disorder in children and adolescents

Article Type: Original Contribution

Keywords: Obsessive compulsive disorder, Cognitive Behaviour Therapy, Randomised controlled trial, Treatment, Young people

Corresponding Author: Dr Tim I Williams, M.A., M.Sc., D.Phil.

Corresponding Author's Institution: Berkshire Healthcare NHS Trust

First Author: Tim I Williams, M.A., M.Sc., D.Phil.

Order of Authors: Tim I Williams, M.A., M.Sc., D.Phil.; Paul M Salkovskis, Ph.D.; Liz Forrester, Ph.D.; Sam Turner, D.Clin. Psych.; Hilary White, D.Clin.Psych.; Mark A Allsopp, M.D.

Abstract: Background: Cognitive behaviour therapy for young people with obsessive compulsive disorder (OCD) has become the treatment of first choice. However the literature is largely based on studies from specialist academic departments and uses methods emphasising exposure and response preveention. In this study we report on a randomised controlled trial of CBT for young people carried out in typical outpatient clinic conditions which focused on responsibility cognitions.

Design: A randomised controlled trial comparing 10 sessions of manualised cognitive behavioural treatment with a 12 week waiting list for adolescents and children with OCD. Assessors were blind to treatment allocation.

Participants: 21 consecutive patients with obsessive-compulsive disorder aged between 9 and 18 years. Results: The group who received treatment improved more than a comparison group who waited for three months. The second group were treated subsequently using the same protocol and made similar gains.

Conclusion: Cognitive behaviour therapy can be delivered effectively to young people with obsessive compulsive disorder in typical outpatient settings.

Response to Reviewers: Thank you for your consideration of our submission to European Child and Adolescent Psychiatry. We have made the following changes to the manuscript in view of the referee's comments. The changes made are described in the order in which they appear in the referee's comments.

Referee's paragraph 1 and 2

I have altered the second paragraph of the introduction to make it clearer that this study was intended to identify whether the Salkovskis model of CBT was usable with young people. I have therefore strengthened the argument for the importance of responsibility cognitions in the introduction, while acknowledging that other models might be supported. A more detailed argument could be produced if 
there was space in the journal. In general the introduction and discussion have been substantially rewritten.

Referee's paragraph 3

We have altered the introduction to de-emphasise the non-academic service based component of the study.

Referee's paragraph 4

The in and exclusion criteria are now described - see also the CONSORT diagram.

Referee's paragraph 5

Further details of the patients have been described including medication, comorbidities and comparability of patients at baseline. Since treatment history was not part of the inclusion or exclusion criteria we have not described it further.

Referee's paragraph 6

We have included further descriptions of the measures that are new to this study, and included information about the CRIQ. Detailed information about these measures is also available on http://psychology.iop.kcl.ac.uk/ocdkids/questionnaires/questionnaires.aspx and in the book edited by Waite \& Williams (2009). The MASC results are now included in the revised manuscript. They were missed out due to an oversight.

Referee's paragraph 7

We have explained that there was no further treatment during the follow-up.

Referee's paragraph 8

We have attempted to make clear that the purpose of the study was not to provide a comparison with other treatments which would require a much larger sample size, but rather to demonstrate that this model of treatment was usable in a clinic setting with young children.

Referee's paragraph 9

While it would be fair to state that our approach was strongly cognitive, it would not be correct to claim that it was purely cognitive. This treatment approach emphasises cognitive change as a means to enable behavioural change. Nevertheless we have attempted to de-emphasise the cognitive approach used here to satisfy the referee's concerns.

Referee's paragraph 10

We have rephrased our point to remove the implied criticism of the Cochrane review

Referee’s paragraph 11

We have removed the word somewhat from the sentence.

Referee’s paragraph 12 
We have clarified the effect sizes used here. Because of the way that the data from the POTS trial has been reported it is not possible to report the Morris \& Deshon type effect size.

Referee's paragraph 13

We have clarified the table to show that the POTS trial contained a placebo condition.

We hope that the revised paper now meets the conditions for publication in ECAP, 
1

2

3

\section{A randomised controlled trial of cognitive behavioural treatment for obsessive compulsive disorder in children and adolescents}

Tim I. Williams, Berkshire Healthcare NHS Trust

\& School of Psychology, University of Reading

Sam Turner, Hilary White, Mark A. Allsopp

Berkshire Healthcare NHS Trust
Paul M. Salkovskis, Liz Forrester Institute of Psychiatry, London

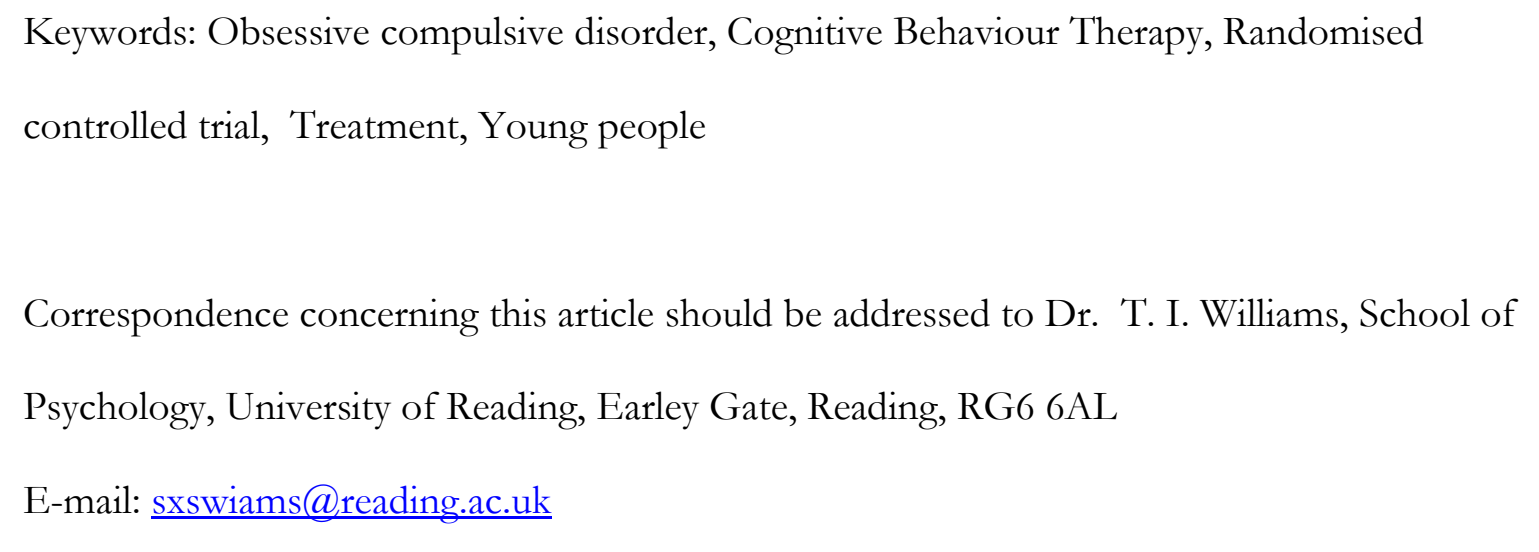

controlled trial, Treatment, Young people

\author{
Correspondence concerning this article should be addressed to Dr. T. I. Williams, School of \\ Psychology, University of Reading, Earley Gate, Reading, RG6 6AL \\ E-mail: sxswiams@,reading.ac.uk \\ Psychology, University of Reading, Eatley Gate, Reading, RG6 6AL
}

Running Head: RCT of CBT for young people with OCD 


\begin{abstract}
Background: Cognitive behaviour therapy for young people with obsessive compulsive disorder (OCD) has become the treatment of first choice. However the literature is largely based on studies from specialist academic departments and uses methods emphasising exposure and response preveention. In this study we report on a randomised controlled trial of CBT for young people carried out in typical outpatient clinic conditions which focused on responsibility cognitions.

Design: A randomised controlled trial comparing 10 sessions of manualised cognitive behavioural treatment with a 12 week waiting list for adolescents and children with OCD. Assessors were blind to treatment allocation.
\end{abstract}

Participants: 21 consecutive patients with obsessive-compulsive disorder aged between 9 and 18 years.

Results: The group who received treatment improved more than a comparison group who waited for three months. The second group were treated subsequently using the same protocol and made similar gains.

Conclusion: Cognitive behaviour therapy can be delivered effectively to young people with obsessive compulsive disorder in typical outpatient settings. 
A randomised controlled trial of cognitive behavioural treatment of obsessive compulsive disorder in children and adolescents

Obsessive compulsive disorder is a particularly severe and disabling psychological disorder. Recent epidemiological studies suggest that it affects around 1.9 to $3.2 \%$ of the adult population and may have a one year prevalence rate of up to $4 \%$ in late adolescence [12]. Follow-up studies have shown that it has a chronic relapsing course such that $50 \%$ of adult patients report their first symptoms in childhood or adolescence and $50 \%$ of patients with obsessive compulsive disorder in adolescence will continue to suffer disabling effects from OCD in adulthood $[2,7,34]$. An effective treatment for OCD in adolescence could offer significant savings for the health service and improved quality of life for many patients.

For adults pharmacological treatments (selective serotonin re-uptake inhibitors; SSRIs) have been shown to reduce the level of symptomatology, but in up to $90 \%$ of patients these gains are lost within seven weeks of stopping treatment [33]. The benefits of SSRIs for young people with OCD have also been demonstrated (see Geller et al., [16] for a meta-analysis) but there are concerns about the safety of medication in young people on the grounds of both physiology and risk taking behaviour. Although controversial, these concerns impact on the acceptability of pharmacotherapy. In adults it is known that SSRIs do not enhance short-term adherence to psychological treatment, and in the long term their use may impair the efficacy of psychological treatments [15].

Recent expert consensus guidelines suggest that cognitive behavioural treatments are the first choice treatments for children and adolescents with OCD [20, 25] although a Cochrane review concluded only that "behavioural or cognitive-behaviour therapy appears to be a promising treatment 
for OCD in children and adolescents" [26]. Until recently there have been few trials which examine the effectiveness of cognitive behavioural therapy for young people, based on the assumption that adult based research would generalise. In general controlled trials have demonstrated that CBT techniques used for adults have generalised well [4, 6, 9, 11, 21]. The largest of these trials [21] demonstrated that both medication and cognitive behavioural therapy were effective treatments for OCD. However there was a significant site by treatment interaction such that in one site cognitive behaviour therapy was significantly more effective than medication whereas in the other site medication was found to be more effective. Other controlled trials of CBT for young people have found similar beneficial effects of CBT compared with medication $[4,11]$.

The components of cognitive behaviour therapy for children have often been poorly specified. Two components have been used by most studies - exposure and response prevention (E/RP) and anxiety management [4, 6, 9, 11, 21]. Bolton and Perrin [9] have demonstrated that $\mathrm{E} / \mathrm{RP}$ alone (with minimal anxiety management) is sufficient to achieve significant benefits. De Haan, Hoogduin, Buitelaar \& Keijsers [11] investigated the use of targeted cognitive techniques including manipulating responsibility cognitions demonstrating comparable effects for CBT and medication. Two studies have delivered CB'T in group format [4,6], without compromising the effect of CBT. Furthermore, Barrett, Healy-Farrell \& March [6] involved parents in treatment with beneficial effects.

An alternative to managing anxiety around exposure and response prevention is to target cognitions specific to OCD. A number of candidate cognitive processes have been suggested and a systematic review of cognitions related to OCD symptoms in young people [27] suggested that three models have some support: increased responsibility; meta-cognitions, and thought-action fusion. These models are difficult to distinguish empirically, because the processes overlap. An appraisal of 
responsibility for intrusive thoughts is a form of meta-cognition (thinking about thoughts) and the appraisal that ones thoughts might result in actions or events occurring is of no significance unless one appraises oneself as responsible for the thought. Evidence for responsibility cognitions being specific to OCD in adults has been provided by Salkovskis and his coworkers who demonstrated that they differentiate patients with OCD from those with other emotional disorders [30].

Studies with young people have not shown the clarity of the link between responsibility and OCD expected from the adult results [27]. Other aspects of cognition such as thought action fusion $[7,18]$, and perfectionism [18] are correlated with symptoms of OCD in young people, although these relationships are substantially mediated by responsibility cognitions [18, 22]. Reynolds and Reeves [27] point out however that the relationships between these cognitive processes are unclear and may be mediated or moderated by other factors such as low mood. The robustness of the responsibility cognitions model in adults and the evidence that responsibility cognitions seem to be problematic in children with OCD suggest that there is utility in examining the extent to which CBT which concentrated on responsibility cognitions could be used to treat OCD.

Salkovskis and his colleagues (e.g. Salkovskis, 1998 [27]) have developed a package of cognitive behavioural treatment methods which concentrates on responsibility cognitions. The components that seem to be particularly important are:

1. normalising the nature of unpleasant intrusive cognitions;

2. identifying the nature of the link between the thoughts and the feelings of discomfort/anxiety and subsequent neutralising rituals;

3. examining the logical nature of the links, and putting them to the test by means of behavioural experiments; 
4. comparing real danger with the worry about causing harm - i.e. discriminating between thinking about and acting upon;

5. helping the patient to identify that the effect of attempting to control the thoughts leads to recurrence of the thoughts or images;

6. helping the patient to consider alternative non-threatening accounts of their obsessive problems.

The therapy also includes psychoeducation about anxiety and an explanation of how trying to carry out exposure and response prevention might seem difficult. Although some exposure work was undertaken, it was always explained in terms of finding out what happens to cognitions and emotions. The therapists did not insist on waiting until the uncomfortable feelings had subsided as is required by exposure and response prevention. A pilot study [35] of this form of CBT with young people suggested that the changes in symptoms were paralleled by the changes in the responsibility beliefs which initiate and maintain compulsive behaviours. The techniques also affect metacognition in that they alter the beliefs about the nature and meaning of cognitions associated with OCD. This form of CBT differs from that used in the POTS trial [21] in its concentration on cognitions. The treatment does not aim to teach the children to resist the impulse to carry out compulsions, but rather to identify and change the misconceptions underlying the motivation to carry out compulsions. A much larger study would be needed to test this form of CBT against other forms of CBT or indeed a purely behavioural treatment such as that in Bolton \& Perrin [9]. 


\section{Methods}

Young people were recruited to the trial with a primary diagnosis of obsessive compulsive disorder based on a semi structured interview for mental health problems (ADIS-C [32]). In total 21 young people aged 9 to 18 years (mean age 13 years 7 months; 13 boys, 8 girls) were recruited from 22 cases referred by Child and Adolescent Mental Health Teams or Family Doctors for the trial (see figure 1 for CONSORT diagram). Children were included if OCD was the major problem, and it had been present for at least six months. Children were excluded if they were unable to speak and understand English fluently, if they had co-occurring psychosis or autism spectrum disorder. At initial assessments 11 presented with no other clinical diagnoses, while four received diagnoses of generalised anxiety disorder, four specific phobia, four separation anxiety, two ADHD, two social phobia, and one dysthymia. (the numbers do not add up to 10 because only two had one additional diagnosis, the others having up to three additional diagnoses). Seven of the participants were taking medication throughout the trial and had been taking the same dose for twelve weeks prior to the trial (two on paroxetine $5 \mathrm{mg} /$ day, 3 on fluoxetine $20 \mathrm{mgs} /$ day, one on fluvoxamine $50 \mathrm{mgs}$ per day, one on clomipramine $50 \mathrm{mgs} /$ day). There was no significant multivariate difference between the groups at initial assessment $(\mathrm{F}(6,13)=0.58$, N.S.) The therapists for the trial (TW, HW, ST) were clinical psychologists employed by the National Health Service (NHS) in England to work in community child and adolescent mental health clinics. All treatment took place in NHS clinics and was recorded on audio tape if the young person consented. 


\section{Procedure}

Once consent was received for taking part in the trial the participants were allocated to either immediate treatment (10 one hour sessions) or a 12 week waiting list. Allocation was carried out on a predetermined random number schedule with no replacements by the trial administrator. Participants in the waiting list condition were informed that they would have to wait twelve weeks for therapy, but they were given the phone number of the lead clinician (TW) to contact in the case of a significant deterioration in OCD.

Assessments were conducted at the beginning and end of treatment (and/or waiting list period), and 12 weeks after the end of treatment. All assessments were completed in the child's home unless specifically requested to be elsewhere. Assessors were blind to the allocation of the participants, and the participants were instructed not to reveal whether they had received treatment. The assessors completed two semi-structured interviews: Children’s Yale-Brown Obsessive Compulsive Scale (C-YBOCS [31]), to assess OCD symptoms and the ADIS-C [32] a semi-structured interview to assess the presence of other comorbid disorders. Participant completed measures included Child Depression Inventory [16], Obsessions and Compulsions Inventory (OCI, [13]) modified for children, Multidimensional Anxiety Scale for Children [18], the Children's Responsibility Attributions Scale (CRAS), the Children's Responsibility Interpretations questionnaire (CRIQ). Both the CRIQ and the CRAS are instruments modified from the adult measures of responsibility cognitions published in Salkovskis et al., [30]). The CRAS is scored such that increasing score indicates a decreasing level of responsibility attributions, whereas the other self report scales are scored such that increasing score indicates increasing difficulties. An unpublished study by the first author found that the internal reliability of the CRAS was good in a large normative sample of 13-14 
year olds (Cronbach's alpha $=0.85)$. The internal reliability in a sample of young people with mental health problems for the other scales was also high (OCI - Cronbach's alpha $=0.93$; RIQ frequency Cronbach's alpha $=0.86$; RIQ belief Cronbach's alpha $=0.85)$. Copies of these measures are available on http://psychology.iop.kcl.ac.uk/ocdkids/questionnaires/questionnaires.aspx.

\author{
Treatments \\ Cognitive behaviour therapy was based on the principles outlined by Salkovskis [28]. \\ Participants worked with their therapists to understand the cognitive distortions which maintain their \\ obsessive compulsive disorder. The aim of treatment is to alter responsibility cognitions, primarily by \\ doing experiments both in session and at home. For instance, one common belief encountered in \\ OCD is that the sufferer is uniquely responsible for harm occurring if certain rituals are not carried \\ out satisfactorily. The therapist and the participant would agree during the session to carry out an \\ experiment designed to see what happens if responsibility is shared. Another common task during \\ therapy is to attempt to elicit the worrying intrusive thoughts and examine whether they have real \\ meaning or are just thoughts. Treatment fidelity was ensured through clinic notes, regular meetings of \\ the therapist team and audiotapes of treatment sessions. \\ Participants were allocated by the trial administrator to the two groups using a table of \\ random numbers. Only the trial administrator was aware which participants were in which group. \\ One participant from each group chose to leave the trial during the first phase, their results have been \\ extrapolated on the conservative assumption that no change occurred as a result of either \\ intervention.
}




\section{Results}

\section{Plan of analysis}

The primary measure of OCD symptoms is the CYBOCS. We report first an analysis of covariance of the CYBOCS score at three months post baseline assessment (with baseline CYBOCS as the covariate), at which stage only one of the two groups will have received an active treatment. This analysis tests the hypothesis that there will be a group effect at three months. We will then repeat the analysis of covariance of the CYBOCS scores at six months post base line when both groups will have received treatment. This analysis tests the hypothesis that there will be a period by group effect on the analysis of the CYBOCS scores at three and six months. Finally we will analyse the secondary measures (i.e. self-report data) in the same way using initial values of the measure as the covariate.

Two clients dropped out of the study during the first phase (one from each condition). In the following analyses the last observation was carried forward from the last available observation. This is therefore an intention to treat analysis.

\section{Analysis of primary measure}

Figure 2 shows the mean CYBOCS scores at baseline, three months and six months. The analysis of covariance (baseline CYBOCS as covariate) of the CYBOCS at 3 months showed a significant group effect $(\mathrm{F}(1)=7.07, \mathrm{p}=0.016)$. The figure shows that this is due to a much improved CYBOCS score for the group treated with CBT first. The group that were allocated to the waiting list showed little or no improvement over the same period. Cohen's effect size (d) for the difference between the two groups divided by the mean standard deviation was calculated as 1.07 , which Cohen (1988) suggested was a large treatment effect.

At 6 months the analysis of covariance of CYBOCS (using baseline CYBOCS as covariate) showed no group effect as expected since both groups had received treatment, although there was a 
trend towards a significant effect of the covariate $(F(1,19)=3.70, p=0.07)$ suggesting that the severity of OCD at the beginning of the trial influences the outcome. As can be seen from figure 2 both groups had improved significantly and the group that was treated first showed continuing slight improvement.

\section{Analysis of secondary measures}

Analysis of the secondary data (the self report questionnaires OCI, CRAS, CDI, CRIQ frequency, CRIQ belief - see table 1) used the same procedures - i.e. analysis of covariance using the baseline value of the measure as the covariate. There were no statistically significant group effects at three months $(\mathrm{OCI}-\mathrm{F}(1,19)=0.29, \mathrm{p}=0.59 ; \mathrm{CDI}-\mathrm{F}(1,19)=0.49, \mathrm{p}=0.49$; CRIQ frequency $-\mathrm{F}(1$, 19) $=2.07 ; \mathrm{p}=0.17 ;$ CRIQ belief $-\mathrm{F}(1,19)=0.90, \mathrm{p}=0.36 ;$ CRAS $\mathrm{F}(1,19)=0.41, \mathrm{p}=0.53 ;$ MASC $\mathrm{F}(1,19)=0.008, \mathrm{p}=0.929)$ but there were significant effects of the covariate for each measure (OCI $\mathrm{F}(1,19)=11.19, \mathrm{p}=0.004 ; \mathrm{CDI}-\mathrm{F}(1,19)=12.20, \mathrm{p}=0.003$; CRIQ frequency $-\mathrm{F}(1,19)=13.06$; $\mathrm{p}=0.002$; CRIQ belief $-\mathrm{F}(1,19)=17.26, \mathrm{p}=0.001 ;$ CRAS $\mathrm{F}(1,19)=27.12, \mathrm{p}<0.001)$, except the MASC $(F(1,19=0.13, \mathrm{p}=0.72)$. Inspection of table 2 shows that show that the groups were improving on all measures at the three month point.

A second analysis of covariance was carried out to determine if the treatment was effective for both groups using data from baseline and at six months after both groups had received CBT. The results showed that there was only a significant time effect $(\mathrm{F}(1,19)=53.14, \mathrm{p}<0.001)$ and no group $(\mathrm{F}(1,19)=0.06, \mathrm{p}=0.82)$ or interaction effect $(\mathrm{F}(1,19)=0.73, \mathrm{p}=0.40)$. As is shown in figure 1 the changes in CYBOCS are largest when the groups are receiving treatment. Overall the CYBOCS scores of the participants reduced from $22.12($ s.e. $=1.08)$ to $9.64($ s.e. $=1.79)$. Analysis of the secondary data also showed significant changes from baseline to six months $(\mathrm{OCI}-\mathrm{F}(1,19)=18.35$, $\mathrm{p}<0.001 ; \mathrm{CDI}-\mathrm{F}=23.16, \mathrm{p}<0.001 ; \mathrm{RIQB}-\mathrm{F}(1,19)=32.8, \mathrm{p}<0.001 ; \mathrm{RIQF}-\mathrm{F}(1,19)=25.15$, 
$\mathrm{p}<0.001 ;$ RAS $-\mathrm{F}(1,19)=10.75, \mathrm{p}=0.004 ;$ MASC $-\mathrm{F}(1,19)=22.81, \mathrm{p}<0.001)$, but no group effects

$(\mathrm{OCI}-\mathrm{F}(1,19)=0.45, \mathrm{p}=0.51 ; \mathrm{CDI}-\mathrm{F}(1,19)=0.53, \mathrm{p}=0.48 ; \mathrm{RIQB}-\mathrm{F}(1,19)=0.30, \mathrm{p}=0.59 ; \mathrm{RIQF}$

$-\mathrm{F}(1,19)=0.003, \mathrm{p}=0.38 ; \mathrm{RAS}-\mathrm{F}(1,19)=0.89, \mathrm{p}=0.36 ; \mathrm{MASC}-\mathrm{F}(1,19)=0.30, \mathrm{p}=0.60)$ or interaction

effects $(\mathrm{OCI}-\mathrm{F}(1,19)=1.41, \mathrm{p}=0.25$; CDI $-\mathrm{F}(1,19)=0.42, \mathrm{p}=0.53$; RIQB $-\mathrm{F}(1,19)=1.03, \mathrm{p}=0.32$;

RIQF $-\mathrm{F}(1,19)=0.83, \mathrm{p}=0.38 ;$ RAS $-\mathrm{F}(1,19)=2.08, \mathrm{p}=0.17 ;$ MASC $-\mathrm{F}(1,19)=0.27, \mathrm{p}=0.61)$. Table 1

shows the means and standard deviations for all the measures.

We followed the recommendations of Morris and Deschon, (2002 cited in Abramowitz et al. [1]) to calculate the effect size as the difference between the immediately pre-treatment CYBOCS and the post treatment CYBOCS divided by the pre-treatment standard deviation $($ effect size $=2.62)$ which also allows for the calculation of the effect size of the placebo. This effect size was compared with those from other published trials which included a control group (see table 2). The results from this study fall within the range of values reported heretofore.

Discussion

Cognitive behaviour therapy largely based on the use of experiments to tackle the cognitive bias of excessive personal responsibility produced a significantly greater reduction in OCD symptoms of the participants than a waiting list condition. Being placed on the waiting list first did not affect the power of the subsequent treatment. The self-report measures showed a statistically significant reduction in self-reported symptoms over the two time periods but did not demonstrate an effect of treatment. The study also shows only small changes in symptoms for the young people placed on the waiting list (cf. Abramovitz et al. [1]) therefore confirming the chronic nature of obsessive compulsive disorder in young people. This adds to the body of evidence in favour of CBT for OCD in young 
people. In view of the potential problems associated with medication, the results of this study support the view that young people with OCD should therefore be offered CBT as the first line treatment by Child and Adolescent mental health services.

This is the first randomised controlled study of a CBT approach based on responsibility cognitions (following Salkovskis $[27,28]$ ) with young people. Although the numbers treated in this trial were small, the demonstration that the treatment was as effective on the waiting list group demonstrates that waiting for treatment had no effect on eventual outcome and increases the power of the study. The study was carried out in routine health service outpatient settings and thus demonstrates that the effectiveness of cognitive behaviour therapy is not restricted to specialist or university research clinics, an effect also seen in the De Haan study [11]. The three month follow up of the group that was treated first suggests that, at least at first, the participants continued to improve after cessation of treatment.

The failure of the self-report measures to demonstrate a difference between the groups at the three month point is difficult to explain. Although a failure to find changes in depression symptoms is not unusual in trials of CBT for OCD [25], we had predicted a change in OCD symptoms paralleling responsibility cognitions as was found in a pilot study [35]. One possibility is that as found by Anholt et al. [3] the changes in behaviour rather than the changes in cognitions were the most significant feature of treatment. However it is also possible that the hope that someone else was going to help with the problem improved the subjective feelings tapped by self report measures including the appraisals of responsibility, but did not alter the assessor rated severity. Yet another possibility is that the self-report measures are not valid in this population. Further research on the validity and reliability of self-report measures would be helpful. 
Other trials of CBT with young people have tended to concentrate on managing the anxiety or discomfort experienced when undertaking exposure and response prevention (e.g. [4,6,21]). The effect size observed in this trial is somewhat less than those seen in previous trials of CBT for young people with OCD (mean effect size 1.98 - Table 3 in Abramovitz et al. [1]), although the differences in the methods of effect size calculation make the comparison somewhat problematic.

Differences in the treatment offered may also be important in determining the effectiveness of the intervention. There are two lines of evidence: intra-trial site differences and inter-trial differences. The POTS trial compared CBT using E/RP and management of the distress associated with OCD with a placebo medication condition but found considerable site differences for both the CBT and a third medication only condition [21]. (Unfortunately because the site data is only reported as Hedge's g effect sizes, we were unable to compare effect sizes using the Morris \& DeShon method [24] and calculated Hedge's g effect sizes in the following text). The Hedge's g effect size for the POTS trial form of CBT varied from 0.51 in Chapel Hill to 1.6 in Pennsylvania (a statistically significant difference). The Hedge's g effect size in this trial (1.07) falls within that range. Bolton \& Perrin [9] demonstrated the benefits of E/RP alone compared with a wait list (Hedge's g effect size 1.23).

Our study does not provide information on the relative merits of different forms of CBT. The difficulty with attempting such a comparison is that the effect sizes of different models of CBT appear to be comparable (see previous paragraph). Of more interest in clinical practice are issues such as the use of combinations of medication and CBT and the involvement of the family. Studies with 
adults have begun to show that offering medication first diminishes the subsequent effectiveness of CBT [15].

Most of the studies on CBT with young people have included the parents in treatment sessions, although Bolton and Perrin [9] only provided feedback at the end of each session. Recent work by Barrett, Healy-Farrell \& March [6] showed that very substantial reductions in OCD could be obtained by the use of family management components in the treatment package. The families of young people with OCD differ in some important respects from the families of young people with anxiety disorders $[5,12]$. Barrett's study demonstrated that the parents were less confident in their child's ability, less rewarding of independence, and were less likely to use positive problem solving than the parents of children with anxiety disorders. Derisley et al. [11] found that parents tended to use avoidant coping techniques as well as having more symptoms of mental health problems. The NICE guidelines too [24] suggest that the contribution of the family to the treatment of young people with OCD needs further investigation. However the involvement of families in the treatment of other emotional disorders in young people has not always been successful [10]. Nevertheless it would be worth investigating whether a family component focused on problem solving strategies and developing confidence in the child's abilities would be helpful in increasing the effect of the CBT used in this study as has been partially demonstrated by Barrett, Healy-Farrell \& March [6]. 


\section{References}

1. Abramowitz, J. S., Whiteside, S. R., \& Deacon, B. J. (2005). The effectiveness of treatment for pediatric obsessive-compulsive disorder: A meta-analysis. Behavior Therapy, 36(1), 55-63.

2. Allsopp, M., \& Verduyn, C. (1989). A Follow-up of Adolescents with Obsessive-Compulsive Disorder. British Journal of Psychiatry, 154, 829-834.

3. Anholt, G. E., Kempe, P., de Haan, E., van Oppen, P., Cath, D. C., Smit, J. H., et al. (2008). Cognitive versus Behavior Therapy: Processes of Change in the Treatment of ObsessiveCompulsive Disorder. Psychother Psychosom, 77(1), 38-42.

4. Asbahr, F. R., Castillo, A. R., Ito, L. M., Latorre, M. D., Moreira, M. N., \& Lotufo-Neto, F. (2005). Group cognitive-behavioral therapy versus sertraline for the treatment of children and adolescents with obsessive-compulsive disorder. Journal of the American Academy of Child and Adolescent Psychiatry, 44(11), 1128-1136.

5. Barrett, P., Shortt, A., \& Healy, L. (2002). Do parent and child behaviours differentiate families whose children have obsessive-compulsive disorder from other clinic and non-clinic families? Journal of Child Psychology and Psychiatry and Allied Disciplines, 43, 597-607.

6. Barrett, P., Healy-Farrell, L., \& March, J. S. (2004). Cognitive-behavioral family treatment of childhood obsessive- compulsive disorder: A controlled trial. Journal of the American Academy of Child and Adolescent Psychiatry, 43, 46-62.

7. Barrett, P., \& Healy-Farrell, L. (2003). Perceived responsibility in juvenile obsessive-compulsive disorder: An experimental manipulation. Journal of Clinical Child and Adolescent Psychology, $\underline{32}, 430-441$.

8. Bolton, D., Luckie, M., \& Steinberg, D. (1995). Long-Term Course of Obsessive-Compulsive Disorder Treated in Adolescence. Journal of the American Academy of Child and Adolescent Psychiatry, 34, 1441-1450. 
9. Bolton, D., \& Perrin, S. (2008). Evaluation of exposure with response-prevention for obsessive compulsive disorder in childhood and adolescence. Journal of Behavior Therapy and Experimental Psychiatry, 39, 11-22.

10. Bodden, D. H. M., Bögels, S. M., Nauta, M. H., De Haan, E., Ringrose, J., Appelboom, C., et al. (2008). Child Versus Family Cognitive-Behavioral Therapy in Clinically Anxious Youth: An Efficacy and Partial Effectiveness Study. Journal of American Academy of Child \& Adolescent Psychiatry, 47(12), 1384-1394.

11. De Haan, E., Hoogduin, K. A. L., Buitelaar, J. K., \& Keijsers, G. P. J. (1998). Behavior therapy versus clomipramine for the treatment of obsessive-compulsive disorder in children and adolescents. Journal of the American Academy of Child and Adolescent Psychiatry, 37, 1022 1029.

12. Derisley, J., Libby, S., Clark, S., \& Reynolds, S. (2005). Mental health, coping and familyfunctioning in parents of young people with obsessive-compulsive disorder and with anxiety disorders. British Journal of Clinical Psychology, 44, 439-444.

13. Douglass, H. M., Moffitt, T. E., Dar, R., McGee, R., \& et al. (1995). Obsessive-compulsive disorder in a birth cohort of 18-year-olds: Prevalence and predictors. Journal of the American Academy of Child and Adolescent Psychiatry, 34, 1424-1431.

14. Foa, E. B., Kozak, M. J., Salkovskis, P. M., Coles, M. E., \& Amir, N. (1998). The validation of a new obsessive-compulsive disorder scale: The Obsessive-Compulsive Inventory. Psychological Assessment, 10, 206-214.

15. Foa, E. B., Liebowitz, M. R., Kozak, M. J., Davies, S., Campeas, R., Franklin, M. E., Huppert, J. D., Kjernisted, K., Rowan, V., Schmidt, A. B., Simpson, H. B., \& Tu, X. (2005). Randomized, placebo-controlled trial of exposure and ritual prevention, clomipramine, and their combination 
in the treatment of obsessive-compulsive disorder. American Journal of Psychiatry, 162, 151 -

161.

16. Geller, D. A., Biederman, J., Stewart, S. E., Mullin, B., Martin, A., Spencer, T., \& Faraone, S. V. (2003). Which SSRI? A meta-analysis of pharmacotherapy trials in pediatric obsessivecompulsive disorder. American Journal of Psychiatry, 160, 1919-1928.

17. Kovacs, M. (1992). The children's depression inventory manual. Toronto: Multi-Health Systems.

18. Libby, S., Reynolds, S., Derisley, J., \& Clark, S. (2004). Cognitive appraisals in young people with obsessive-compulsive disorder. Journal of Child Psychology and Psychiatry, 45, 1076-1084.

19. March JS (1997). Technical Manual for the Multidimensional Anxiety Scale for Children (MASC). New York: Multi-Health Systems.

20. March, J.S., Frances, A., Carpenter, D. and Kahn, M.D., (1997) Treatment of obsessivecompulsive disorder. The Expert Consensus Panel for obsessive-compulsive disorder. Journal of Clinical Psychiatry, 58 Suppl 4, 2-72.

21. March, J. S., Foa, E., Gammon, P., Chrisman, A., Curry, J., Fitzgerald, D., Sullivan, K., Franklin, M., Huppert, J., Rynn, M., Zhao, N., Zoellner, L., Leonard, H., Garcia, A., Freeman, J., \& Tu, X. (2004). Cognitive-behavior therapy, sertraline, and their combination for children and adolescents with obsessive-compulsive disorder - The Pediatric OCD Treatment Study (POTS) randomized controlled trial. Journal of the American Medical Association, 292, 1969-1976.

22. Mather, A., \& Cartwright-Hatton, S. (2004). Cognitive predictors of obsessive-compulsive symptoms in adolescence: A preliminary investigation. Journal of Clinical Child and Adolescent Psychology, 33, 743-749.

23. Matthews, L., Reynolds, S., \& Derisley, J. (2006). Examining cognitive models of obsessive compulsive disorder in adolescents. Behavioural and Cognitive Psychotherapy, 35(02), 149-163. 
24. Morris, S.B. and DeShon, R.P. (2002) Combining Effect Size Estimates in Meta-Analysis With Repeated Measures and Independent-Groups Designs. Psychological Methods, 7, 105-125.

25. National Collaborating Centre for Mental Health (2006) Obsessive compulsive disorder: Core interventions in the treatment of obsessive compulsive disorder and body dysmorphic disorder. National Clinical Practice Guideline Number 31. London: The British Psychological Society \& The Royal College of Psychiatrists.

26. O’Kearney R.T., Anstey, K.J., \& von Sanden, C. (2006) Behavioural and cognitive behavioural therapy for obsessive compulsive disorder in children and adolescents. $\underline{\text { Cochrane Database of }}$ Systematic Reviews, Issue 4. Art. No.: CD004856. DOI:10.1002/14651858.CD004856.pub2.

27. Reynolds, S., \& Reeves, J. (2008). Do Cognitive Models of Obsessive Compulsive Disorder Apply to Children and Adolescents? Behavioural and Cognitive Psychotherapy, 36(04), 463-471.

28. Salkovskis, P. M. (1998). Psychological approaches to the understanding of obsessional problems. In R. P. Swinson, M. M. Antony, S.J. Rachman, and Richter, M.A. (Ed.), Obsessivecompulsive Disorder: theory, research and treatment. New York: Guilford.

29. Salkovskis, P. M. (1999). Understanding and treating obsessive-compulsive disorder. Behaviour Research and Therapy, 37, s29-52.

30. Salkovskis, P., Wroe, A., Gledhill, A., Morrison, N., Forrester, E., Richards, C., Reynolds, M., \& Thorpe, S. (2000). Responsibility attitudes and interpretations are characteristic of obsessive compulsive disorder. Behaviour Research and Therapy, 38, 347-372.

31. Scahill, L., Riddle, M. A., McSwiggin Hardin, M., Ort, S. I., King, R. A., Goodman, W. K., Cicchetti, D., \& Leckman, J. F. (1997). Children's Yale-Brown Obsessive Compulsive Scale: reliability and validity. Journal of the American Academy of Child and Adolescent Psychiatry, $\underline{36}, 844-852$. 
32. Silverman, W. K., \& Albano, A. M. (1996). Anxiety disorders interview schedule for DSM-IV: $\underline{\text { Child and parent versions. San Antonio: The Psychological Corporation. }}$

33. Simpson, H. B., Franklin, M. E., Cheng, J. F., Foa, E. B., \& Liebowitz, M. R. (2005). Standard criteria for relapse are needed in obsessive-compulsive disorder. Depression and Anxiety, 21, 18.

34. Thomsen, P. H., \& Mikkelsen, H. U. (1995). Course of obsessive compulsive disorder in children and adolescents. A prospective follow-up study of 23 Danish cases. Journal of the American Academy of Child and Adolescent Psychiatry, 34, 1432-1440.

35. Williams, T., Salkovksis, P., Forrester, E. A., \& Allsopp, M. A. (2002). Changes in Symptoms of OCD and Appraisal of Responsibility During Cognitive Behavioural Treatment: A Pilot Study. Behavioural and Cognitive Psychotherapy, 30, 69-78. 


\section{Author Note}

Tim I Williams is Honorary Research Fellow at the School of Psychology, University of Reading and Consultant Clinical Psychologist with the Berkshire Healthcare NHS Trust. Professor Salkovskis and Dr Forrester are at the Department of Psychology at the Institute of Psychiatry, Kings College, University of London. Dr Mark Allsopp is Consultant Child and Adolescent Psychiatrist, Berkshire Adolescent Service, Berkshire Healthcare Foundation Trust, Wokingham Hospital. This research was supported by a grant (SPGS 808) from the National Health Service Responsive Funding Scheme to the first author. 
Table 1

Means (s.e.) of self-report measures at baseline, three months (after first phase - one group treated) and six months (after second phase - both groups treated)

Baseline $\quad 3$ months 6 months

Measure

\begin{tabular}{|c|c|c|c|c|c|c|}
\hline & CBT & WL & CBT & WL & CBT & WL \\
\hline \multirow{2}{*}{ CYBOCS } & 23.09 & 21.05 & 12.09 & 19.60 & 9.23 & 10.10 \\
\hline & $(1.22)$ & $(1.84)$ & $(2.25)$ & $(2.03)$ & $(2.45)$ & $(2.74)$ \\
\hline \multirow{2}{*}{ OCI } & 59.30 & 73.55 & 45.00 & 60.30 & 37.10 & 34.30 \\
\hline & $(8.28)$ & $(8.26)$ & $(8.30)$ & $(9.62)$ & $(8.73)$ & $(5.51)$ \\
\hline \multirow{2}{*}{ CDI } & 17.85 & 14.67 & 12.9 & 12.78 & 10.50 & 9.06 \\
\hline & $(2.76)$ & $(1.82)$ & $(2.62)$ & $(2.92)$ & $(2.41)$ & $(2.56)$ \\
\hline \multirow{2}{*}{ MASC } & 59.8 & 66.3 & 49.7 & 56.6 & 41.1 & 43.0 \\
\hline & $(6.87)$ & $(6.74)$ & $(5.90)$ & $(6.69)$ & $(4.40)$ & $(7.28)$ \\
\hline \multirow{2}{*}{ CRAS } & 49.00 & 51.00 & 58.00 & 63.63 & 58.00 & 74.13 \\
\hline & $(6.00)$ & $(8.10)$ & $(7.54)$ & $(6.15)$ & $(8.03)$ & $(8.31)$ \\
\hline \multirow{2}{*}{ CRIQ Belief } & 634.38 & 781.11 & 563.13 & 537.78 & 320.63 & 332.22 \\
\hline & $(103.66)$ & $(152.50)$ & $(99.26)$ & $(150.76)$ & (86.94) & $(102.34)$ \\
\hline \multirow{2}{*}{ CRIQ Frequency } & 29.25 & 31.44 & 25.38 & 19.33 & 16.75 & 13.89 \\
\hline & $(4.31)$ & $(5.14)$ & $(3.90)$ & $(5.45)$ & $(4.36)$ & $(4.35)$ \\
\hline
\end{tabular}


Table 2

Effect sizes on CYBOCS calculated according to Morris and Schon (2002) for controlled studies of CBT in young people.

\begin{tabular}{ccc}
\hline Study & Individual CBT effect size & Waiting list or placebo \\
& & control effect size \\
\hline This study & -2.61792 & -0.24914 \\
March et al. 2004 & -2.6087 & -0.81818 \\
(placebo) & -2.10169 & N/A \\
De Haan et al. 1998 & -3.55349 & 0.198543 \\
Barrett et al. 2004 & \\
\hline Table notes: Negative numbers indicate improved CYBOCS scores. N/A indicates \\
that the study did not include a waiting list control
\end{tabular}




\section{Figure Captions}

Figure 1. Consort diagram.

Figure 2. Mean CYBOCS scores for both groups at baseline, three months and six months. Error bars represent standard errors of the mean at each time point. 


\section{Assessed for eligibility $(\mathrm{n}=22)$}
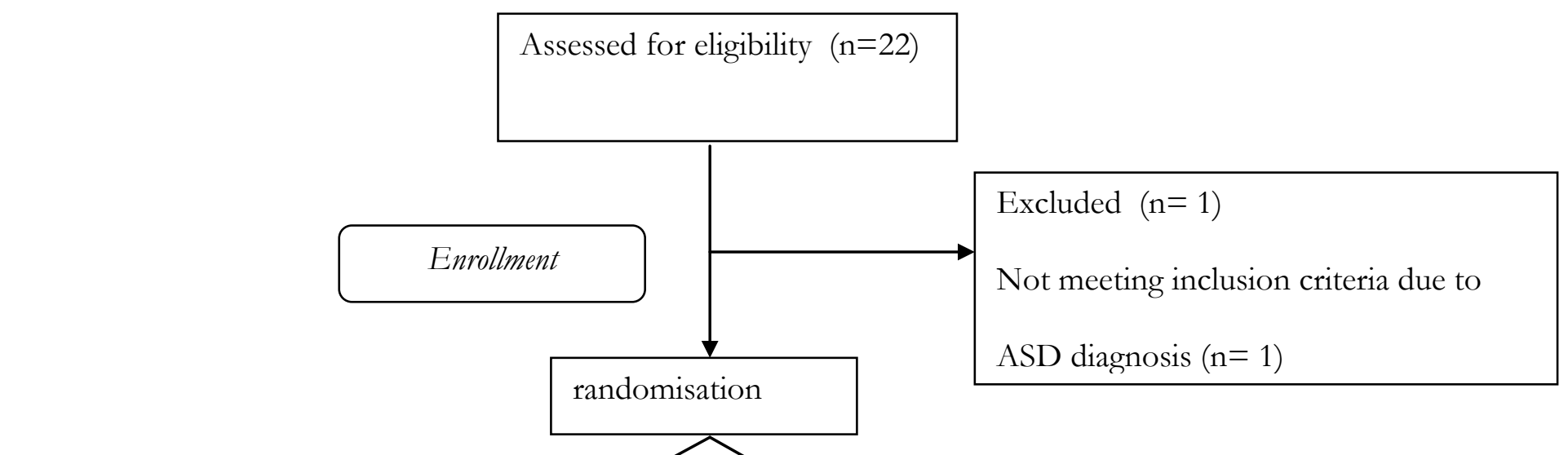

ASD diagnosis $(n=1)$

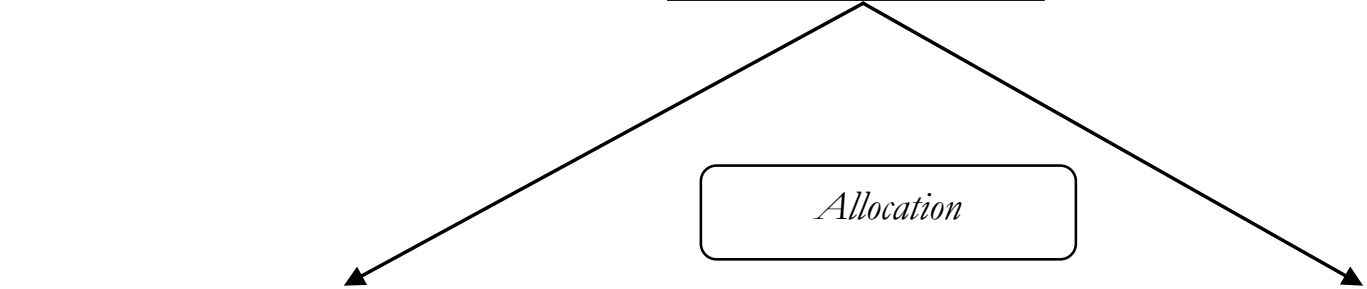

Allocated to CBT $(\mathrm{n}=11)$

Received allocated intervention $(\mathrm{n}=11)$

Did not receive allocated intervention $(n=0)$

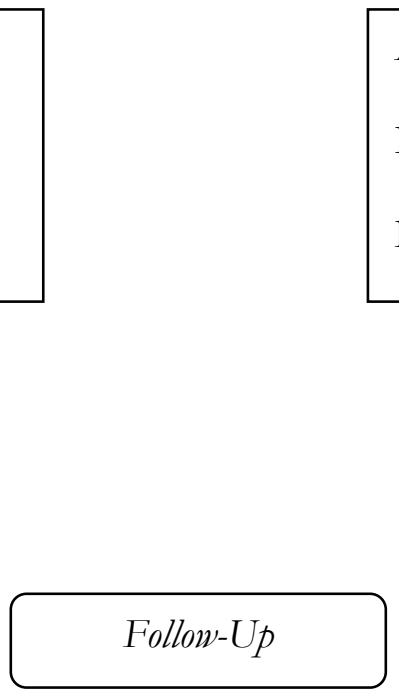

Allocated to wait list $(\mathrm{n}=10)$

Received allocated intervention $(n=10)$

Did not receive allocated intervention $(\mathrm{n}=0)$

\section{Lost to follow-up $(n=1)$}

Refused CBT part way through

course - no longer willing to engage with therapist

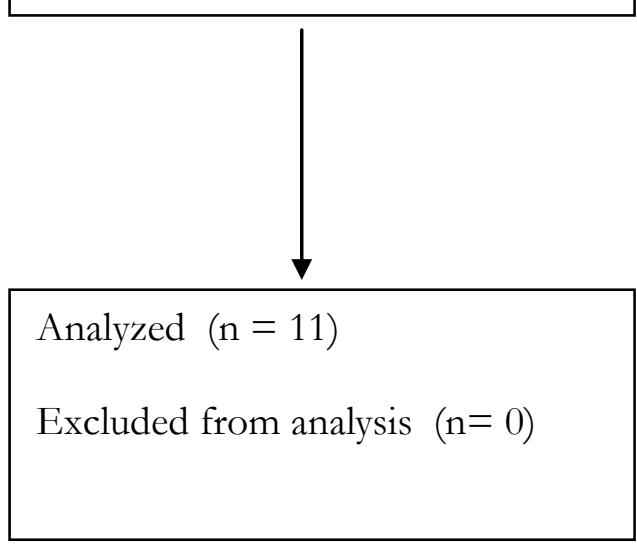

Lost to follow-up $(n=1)$

Unable to tolerate waiting list, sought treatment elsewhere

Analyzed $(n=10)$

Excluded from analysis $(\mathrm{n}=0)$ 


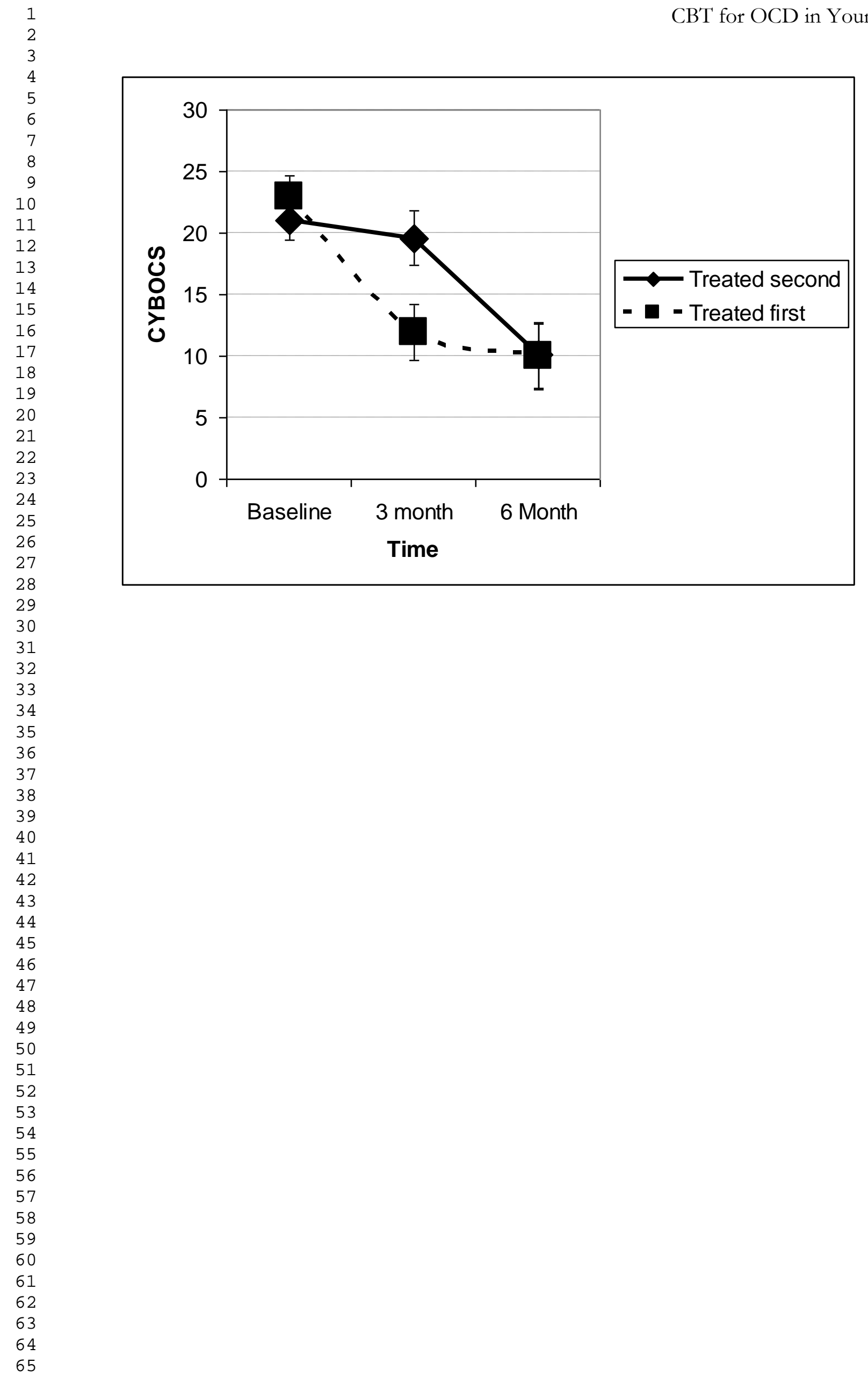


Head of Department

Dr. J. Elllis

The Editor

European Child and Adolescent Psychiatry

\section{The University of Reading}

School of Psychology

Earley Gate

Reading RG6 6AL

$\begin{array}{ll}\text { Phone } & +44(0) 1183786604 \\ \text { Fax } & +44(0) 1183786715 \\ \text { Email } & \text { sxswiams@reading.ac.uk } \\ \text { Web } & \text { www.rdg.ac.uk/ }\end{array}$

Monday, 30 March 2009

Dear Sir,

Submission no.

Thank you for your consideration of our submission to European Child and Adolescent Psychiatry. We have made the following changes to the manuscript in view of the referee's comments. The changes made are described in the order in which they appear in the referee's comments.

Referee's paragraph 1 and 2

I have altered the second paragraph of the introduction to make it clearer that this study was intended to identify whether the Salkovskis model of CBT was usable with young people. I have therefore strengthened the argument for the importance of responsibility cognitions in the introduction, while acknowledging that other models might be supported. A more detailed argument could be produced if there was space in the journal. In general the introduction and discussion have been substantially rewritten.

Referee's paragraph 3

We have altered the introduction to de-emphasise the non-academic service based component of the study.

Referee's paragraph 4

The in and exclusion criteria are now described - see also the CONSORT diagram.

Referee's paragraph 5 
Further details of the patients have been described including medication, comorbidities and comparability of patients at baseline. Since treatment history was not part of the inclusion or exclusion criteria we have not described it further.

\section{Referee's paragraph 6}

We have included further descriptions of the measures that are new to this study, and included information about the CRIQ. Detailed information about these measures is also available on http://psychology.iop.kcl.ac.uk/ocdkids/questionnaires/questionnaires.aspx and in the book edited by Waite \& Williams (2009). The MASC results are now included in the revised manuscript. They were missed out due to an oversight.

\section{Referee's paragraph 7}

We have explained that there was no further treatment during the follow-up.

Referee's paragraph 8

We have attempted to make clear that the purpose of the study was not to provide a comparison with other treatments which would require a much larger sample size, but rather to demonstrate that this model of treatment was usable in a clinic setting with young children.

\section{Referee's paragraph 9}

There is a consistent thread in this referee's comments that suggests that they have over-emphasised the cognitive nature of our approach. While it would be fair to state that our approach was strongly cognitive, it would not be correct to claim that it was purely cognitive. This treatment approach emphasises cognitive change as a means to enable behavioural change. Nevertheless we have attempted to de-emphasise the cognitive approach used here to satisfy the referee's concerns.

\section{Referee's paragraph 10}

We have retained the sentence about O'Kearney et al.'s Cochrane review being overly pessimistic, but removed the phrase about the number of studies included. We hope that the referee would agree that the review might be considered over-pessimistic, the use of the word suggests indicates that we are not stating this as a fact but rather as an opinion. 
Page 3

Referee's paragraph 11

We have removed the word somewhat from the sentence.

Referee's paragraph 12

We have clarified the effect sizes used here. Because of the way that the data from the POTS trial has been reported it is not possible to report the Morris \& Descon type effect size.

Referee's paragraph 13

We have clarified the table to show that the POTS trial contained a placebo condition. 